\title{
Anabases
}

ANABASES Traditions et réceptions de l'Antiquité

$21 \mid 2015$

Varia

\section{Frédéric DUVAL, Dire Rome en français. Dictionnaire onomasiologique des institutions}

\section{Luigi-Alberto Sanchi}

\section{(2)enEdition}

\section{Journals}

Édition électronique

URL : http://journals.openedition.org/anabases/5343

DOI : 10.4000/anabases.5343

ISSN : 2256-9421

\section{Éditeur}

E.R.A.S.M.E.

\section{Édition imprimée}

Date de publication : 1 avril 2015

Pagination : 267-268

ISSN : 1774-4296

\section{Référence électronique}

Luigi-Alberto Sanchi, «Frédéric duval, Dire Rome en français. Dictionnaire onomasiologique des institutions », Anabases [En ligne], 21 | 2015, mis en ligne le 01 avril 2015, consulté le 22 septembre 2020. URL : http://journals.openedition.org/anabases/5343 ; DOI : https://doi.org/10.4000/anabases 5343

Ce document a été généré automatiquement le 22 septembre 2020

(c) Anabases 


\title{
Frédéric DUVAL, Dire Rome en français. Dictionnaire onomasiologique des institutions
}

\author{
Luigi-Alberto Sanchi
}

\section{RÉFÉRENCE}

Frédéric DUVAL, Dire Rome en français. Dictionnaire onomasiologique des institutions, Genève, Droz, 2012, Publications romanes et françaises 257, 468 p.

66 euros / ISBN 978-2-600-01597-4

1 Ce miroir très précis des relations lexicales étroites qu'a entretenues la littérature médiévale en français avec le patrimoine intellectuel de la Rome antique, même limité aux « institutions » (selon la perspective de l'Histoire des institutions de J. Ellul : voir l'Introduction, p. 24-25), ne manquera pas d'attirer l'attention des lecteurs et des chercheurs passionnés par les réceptions de l'Antiquité. La méthode d'analyse " onomasiologique " annoncée dans le sous-titre part des " concepts ", ici indiqués en latin (choix justifié dans l'Introduction, p. 37), pour en développer l'étude sémantique à travers les expressions auxquelles chaque concept donne lieu dans la langue voulue, ici l'ancien français.

2 Sans doute aurait-on pu employer le terme de thésaurus, car ce " dictionnaire ", loin de suivre l'ordre alphabétique des concepts retenus, les organise de manière nécessairement hiérarchisée. Grâce à la table des matières en fin de volume et à la " table des concepts » (p. 465-468), le lecteur découvre ainsi l'ordre choisi par F. Duval et motivé dans l'Introduction, p. 34-37 - pour répartir la masse de notions au sein de chapitres cohérents, d'ampleur inégale : I. " Exercice suprême du pouvoir » (décliné en plusieurs sections, comme "Principes généraux ", " Royauté ", " Empire ", p. 61-96) ; II. "Les organes du gouvernement " (comprenant le "Sénat ", les " Assemblées du peuple », jusqu'au «Personnel subalterne », p. 97-333) ; III. « Le 
peuple romain » (citoyens, hommes libres, esclaves, p. 335-424) et IV. « Le statut des terres et de leurs habitants " (Latins, alliés, provinces, municipes..., p. 446).

Pour ne donner qu'un exemple des niveaux hiérarchiques inférieurs, jusqu'aux expressions françaises correspondantes, prenons l'entrée "Libertus ", qui se trouve insérée sous le $\$ 4$ ( Affranchissement ») de la section « Liberté et esclavage » dans le chapitre III cité plus haut (" Le peuple romain »). Sous le concept de "Libertus » sont rassemblés plusieurs lemmes latins : les noms « libertus, libertinus », "liberta, libertina » et « libertinus », traités aux p. 415-421. On y trouve toutes les expressions présentes dans le large corpus français étudié par l'Auteur et découlant de ces noms latins ; au nombre de seize pour " libertus, libertinus », elles vont de " serf et puis franchi » à " sergent mis hors de servage " et à " qui est affranchi et par avant a esté serf ", en passant par " libertin ", " liberte ", " fils d'un vilain serf " ou, entre autres, " jadis homme serf qui lors estoit affranchi ». Chacune de ces traductions fait l'objet d'un développement, rédigé avec un minimum d'abréviations fastidieuses, donnant sa source, son contexte et son emploi et ajoutant d'utiles commentaires. Après l'analyse de tous les lemmes concernés, l'auteur offre (p.421) une commode "Synthèse de Libertus ", c'est-à-dire une vue d'ensemble de tous les lemmes compris sous le concept étudié, qui commence ici par rappeler que la lexicographie médiolatine « simplifie le système classique en opposant le libertus (affranchi) au libertinus (fils d'affranchi), alors qu'en latin classique libertinus a les deux sens ».

4 Certaines synthèses d'entrées très fouillées sont précédées d'un tableau récapitulatif ; c'est le cas, p. 155, pour celle relative au concept de " Magistratus » dans les deux sens de magistrat et de magistrature, p. 141-154. Pour consulter l'ouvrage à partir des mots français, on peut consulter l'Index verborum (p. 449-459) qui réunit toutes les unités lexicales françaises, y compris celles qui entrent dans les périphrases citées : ainsi « vilain " (présent dans l'expression " fils d'un vilain serf ») et "liberte » font également l'objet de renvois au lemme cité Libertus, libertinus.

5 Le large corpus français à la base des différentes entrées s'ouvre sur le début du XIII ${ }^{e}$ siècle et est borné par un terminus ad quem très classique, à savoir l'an 1500 (voir à ce propos les considérations de l'auteur, p.25-26). Ce corpus comprend, bien sûr, de nombreuses traductions, de Végèce, du Digeste, de Cicéron, de Boèce, de Térence... mais aussi celles du Speculum historiale ou du Policraticus, ainsi que des abrégés d'histoire, des vies de saints, le Trésor de Brunetto Latini, les traités politiques de Christine de Pisan Le Chemin de longue étude et Le livre du corps de policie (voir la liste détaillée p. 26-30 ; des " Compléments " sont énumérés p.33-34). Soulignons aussi la clarté avec laquelle les difficultés orthographiques et grammaticales inhérentes à l'ancien français ont été groupées, analysées, simplifiées (voir p. 37-42) pour aider la lisibilité sans renoncer à la précision scientifique.

6 Situé au confluent de l'histoire, de la linguistique et de la philologie et reposant sur une vaste bibliographie (voir p. 44-57), ce travail à la fois original, rigoureux et généreux permet d'interroger avec pertinence et sur un terrain balisé le rapport complexe - « dialectique ", comme le déclare la présentation en quatrième de couverture - du grand Moyen Âge français des $\mathrm{XIII}^{\mathrm{e}}-\mathrm{XV} \mathrm{e}^{\mathrm{e}}$ siècles avec le passé antique, notamment romain impérial, et sa curiosité pour les éléments encyclopédiques de la civilisation hellénistique-romaine, tour à tour historiques et philosophiques, juridiques, politiques, administratifs, militaires ou techniques. 


\section{AUTEURS}

\section{LUIGI-ALBERTO SANCHI}

CNRS - Institut d'histoire du droit, Paris

luigi-alberto.sanchi@u-paris2.fr 